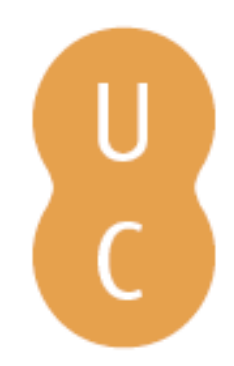

\title{
pommalina
}

\section{A Europa sob os auspícios de um novo Reich: regionalismo e universalismo na obra de Carl Schmitt}

\author{
Autor(es): $\quad$ Goulart, Mayra \\ Publicado por: Imprensa da Universidade de Coimbra \\ URL \\ persistente: URI:http://hdl.handle.net/10316.2/47439 \\ DOI: $\quad$ DOI:https://doi.org/10.14195/978-989-26-1524-0_15 \\ Accessed : $\quad$ 26-Apr-2023 13:08:52
}

A navegação consulta e descarregamento dos títulos inseridos nas Bibliotecas Digitais UC Digitalis, UC Pombalina e UC Impactum, pressupõem a aceitação plena e sem reservas dos Termos e Condições de Uso destas Bibliotecas Digitais, disponíveis em https://digitalis.uc.pt/pt-pt/termos.

Conforme exposto nos referidos Termos e Condições de Uso, o descarregamento de títulos de acesso restrito requer uma licença válida de autorização devendo o utilizador aceder ao(s) documento(s) a partir de um endereço de IP da instituição detentora da supramencionada licença.

Ao utilizador é apenas permitido o descarregamento para uso pessoal, pelo que o emprego do(s) título(s) descarregado(s) para outro fim, designadamente comercial, carece de autorização do respetivo autor ou editor da obra.

Na medida em que todas as obras da UC Digitalis se encontram protegidas pelo Código do Direito de Autor e Direitos Conexos e demais legislação aplicável, toda a cópia, parcial ou total, deste documento, nos casos em que é legalmente admitida, deverá conter ou fazer-se acompanhar por este aviso.

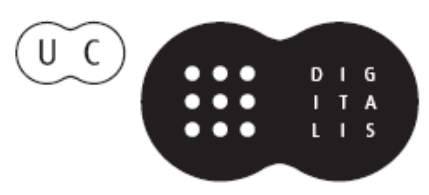


JOSÉ MANUEL PUREZA JOSÉ JUSTE RUIZ (COORDS.)
IMPRENSA DA

UNIVERSIDADE

DE COIMBRA

COIMBRA

UNIVERSITY

PRESS
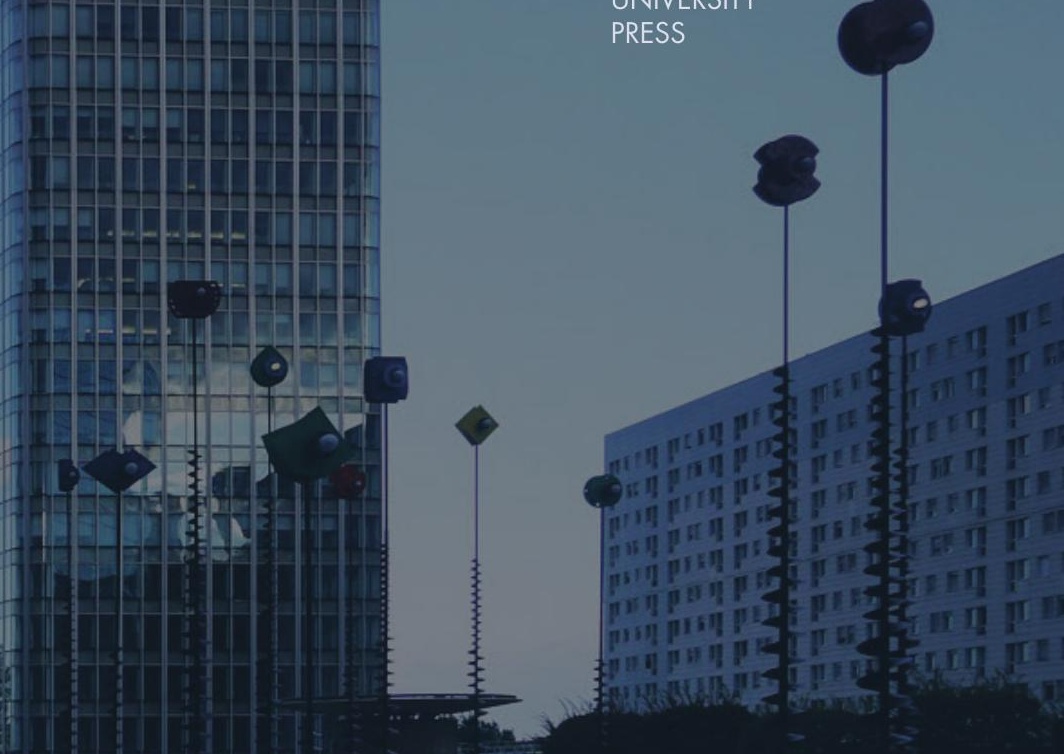

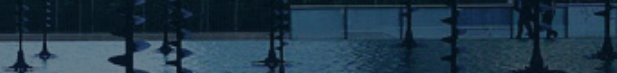

OS ESTADOS

EA ORDEM

INTERNACIONAL

CONTEMPORANEA

ATAS DO V ENCONTRO LUSO-ESPANHOL DE Professores de Direito internacional e RELAÇÕES INTERNACIONAIS 


\section{A EUROPA SOB OS AUSPÍCIOS DE UM NOVOREICH: REGIONALISMO E UNIVERSALISMO NA OBRA DE CARL SCHMITT}

\section{Mayra Goulart}

\section{Introdução}

O nome de Carl Schmitt segue sendo uma das principais referências em termos de teoria jurídica e política do período da República de Weimar. Sua crítica ao liberalismo, postulada em "O Conceito do Político", de 1932, é indubitavelmente a parte mais notória de sua longa carreira, iniciada antes da Primeira Guerra Mundial, estendendo-se de forma quase ininterrupta até 1978, quando Schmitt, aos 90 anos, publica seu último artigo, "The Legal World Revolution".

Entretanto, a aproximação do autor com o Partido Nazista, em 1933, acabou marginalizando suas contribuições e influenciando as interpretações tanto das obras publicadas anteriormente a sua afiliação, como, em particular, as do período posterior ao seu desligamento, que ocorre em 1936. A partir desta data, Schmitt busca um afastamento das teses que o fizeram ser visto como o Crown jurist do Terceiro Reich ${ }^{1}$, afastando-se as discussões sobre política doméstica, em favor de indagações orientadas para o plano das re-

${ }^{1}$ No livro "Theorist for the Reich", Joseph Bendersky, relata o envolvimento intelectual de Schmitt, enquanto jurista proeminente no contexto alemão da década 
lações internacionais (Bendersky, 1983). A principal obra desta fase é o livro O Nomos da Terra: no Direito dos Povos do Jus publicum europaeum, publicado em 1950.

O texto é dedicado a uma análise da ascensão e do ocaso do Jus publicum europaeum (Direito dos Povos europeu), sistema que, segundo o autor, teria sido capaz de estruturar as relações entre os diferentes Estados do continente, durante o que se denomina como Pax Westphaliana. Nesta medida, seguindo a argumentação esboçada por Schmitt, a decadência de tal ordenamento teria dado origem a um período incerteza e instabilidade no plano internacional, haja vista a indefinição no padrão de articulação entre espaço/ território e autoridade/poder (Rasch, 2005).

Não obstante, no que diz respeito ao presente artigo, essa discussão servirá como fio condutor para uma análise da atual situação do sistema internacional marcado pela ambiguidade entre uma ordem em que convivem princípios nacionalistas (estadocêntricos), universalista se regionalistas. No tocante aos últimos, Schmitt, oferece uma interessante abordagem acerca da divisão do globo em áreas de influência sob os auspícios de uma potência regionalmente hegemônica. Estas áreas recebem o nome de Großraum, literalmente "grande espaço" (Schmitt, 1979).

Quando aplicada ao fenômeno de regionalização, característico da nova ordem mundial essa categoria espacial, entre o Estado e o universo, torna-se um instrumento útil para a análise da conjuntura que deflagra-se com o fim da Guerra Fria ${ }^{2}$. É sob esse prisma

de 30 , assim como comenta as conseqüencias desse envolvimento para a carreira e vida do autor.

${ }^{2}$ Conforme o argumento aqui desenvolvido, embora seja passível de enquadrar a situação da Alemanha na configuração atual da União Européia, o conceito de Großraum, fora concebido em um momento anterior ao estabelecimento da hegemonia econômica e política do país, uma vez que o autor, falecido em 1985, não viveu para ver sua pátria finalmente assumir a posição de Reich, em face dos demais países do continente. 
que Schmitt nos narra a dissolução do chamado Nomos da Terra, enquanto ordem estadocêntrica, apresentando a possibilidade de que, a partir de suas cinzas, surja um novo sistema global, no qual o Estado, no sentido westphaliano, deixa de ser o principal sujeito das relações internacionais (Peter Stirk, 1999). Nesta medida, o objetivo do presente trabalho é resgatar essa mudança na forma de integrar e articular as diferentes regiões e povos, conforme apresentada por Schmitt, levando emconsideração seu esforço de conciliar a análise histórica do processo de transformação narealidade material e nos conceitos que os homens utilizam para ordená-la. Sob essa lente teórica,observar-se-á o dilema entre duas tendências contraditórias. O regionalismo - que se traduz naconstrução de uma ordem orientada por princípios realistas de divisão de poder, entre blocos regionais com identidades heterogêneas -; e o universalismo - traduzido nos princípios idealistas sintetizados na Declaração Universal dos Direitos do Homem.

\section{A Pax Westiphaliana enquanto Nomos da Terra}

O conceito de Nomos da Terra diz respeito a um período da história europeia caracterizado pela formação de um sistema jurídico-normativo composto por um conjunto de regras capazes de regular os conflitos surgidos entre os diferentes povos europeus, diminuindo sua intensidade. Essa capacidade de regulação, na qual radicaria, segundo Schmitt, a grande vantagem deste sistema, não seria derivada das próprias normas que o compunham, mas do seu enraizamento em uma organização espacial concreta, isto é, da divisão do continente europeu em Estados-nação (Schmitt, 1979).

Sob esta perspectiva, que enseja a argumentação defendida ao longo deste trabalho, o conceito de Nomos da Terra, apesar de historicamente referenciado, possui também uma função instrumental, 
sendo passível de ser mobilizado com o objetivo de direcionar a reflexão no plano do direito internacional para aquela que seria a sua função primordial: a criação de medidas capazes de solucionar as questões espaciais de apropriação, divisão e distribuição do solo, de forma a regular os conflitos (Buchard, 2006).

Estruturado por esta hipótese, o livro O Nomos da Terra narra a transformação nas categorias usadas para pensar o direito internacional, relacionando-a com o que seriam as conseqüências dessa mudança no plano jurídico-conceitual. O conceito de Nomos da Terra, portanto, é mobilizado para demonstrar como a transformação dessas categorias e a dissolução do Ius publicum europaeum teria dado origem, no início do século XX, a um novo sistema internacional incapaz de organizar o espaço e regular os conflitos (Luoma-Aho, 2000).

O sistema chamado por Schmitt de Nomos da Terra teria surgido no século XVI. Esta seria uma época de intensas transformações no modo de apreender o espaço, derivadas do avanço das ciências, da navegação e da descoberta de novos territórios e povos. O novo aparato tecnológico teria, pois, permitido que fosse ampliada a concepção de mundo, que passa a incluir efetivamente todo o planeta. Só quando se torna possível apreender a totalidade do espaço global - seja cientificamente, por meio de mapas, ou empiricamente, por meio das grandes navegações - é que pôde surgir o primeiro Nomos da Terra, enquanto ordenação global do espaço, realizada pelo Direito dos Povos europeu.

Neste mesmo contexto, observa-se uma articulação entre as dimensões terrestre e marítima, ou, na terminologia do autor, entre terra firme - no caso a Europa continental - e mar livre, definido por Schmitt como um espaço no qual as divisões e demarcações que evidenciam ou legitimam a apropriação e a divisão de seu espaço não podem se fixar com clareza e visibilidade. Nesse caso, os adjetivos firme e livre, dizem respeito à configuração de um espaço aberto ou não à disputa entre os povos, o que estaria diretamente 
vinculado à estatalidade (Schmitt, 1952). A contraposição entre essas duas dimensões é fundamental. É por meio dela que se constituiu o sistema jurídico internacional europeu, estruturado, segundo a argumentação do autor, a partir da oposição entre duas esferas com regras e valores antitéticos, a do mar e a da terra, que nesse período é dividida em Estados-Nação, cada qual indiscutivelmente soberano dentro de seu território fixo e delimitado por fronteiras. Seguindo a argumentação do autor, é por causa deste princípio espacial de organização que o plano terrestre, pelo menos dentro do continente europeu, deixa de ser um espaço aberto à conquista, passando a estar estruturado por noções jurídicas de propriedade que regulam as relações entre os indivíduos e entre os Estados (Schmitt, 1979).

Ademais, em virtude do caráter estruturante da diferenciação entre terra e mar, o surgimento desse sistema de ordenamento das relações internacionais, enquadrado por Schmitt no conceito de Nomos da Terra, é articulado à emergência da Inglaterra como grande potência hegemônica nos mares, mas estreitamente ligada à ordenação terrestre. A tese de Schmitt é que o Ius publicum europaeum, só pôde funcionar porque se configurou a partir de uma base concreta que era a própria divisão espacial do continente europeu em territórios estatais com fronteiras fixas que, por conseguinte, se contrapõe ao caráter fluido do mar, e mesmo dos outros continentes, concebidos como espaços abertos à disputa e à conquista, no qual os conflitos e o uso da violência não eram alvo de qualquer regulação (Schmitt, 1979).

É nesse sentido que este enquadramento conceitual se torna interessante para operacionalizar uma crítica à ordem internacional capitaneada, no início do século XXI, pela Liga das Nações e, posteriormente, aprofundada com assinatura da Carta das Nações Unidas, cujo propósito é fundar um sistema global baseado em princípios humanitários e igualitários, transcendentes a quaisquer determinantes territoriais ou culturais. 
Recuperando a argumentação do autor, é possível atribuir a este novo paradigma de direito internacional, um conteúdo abstrato, desenraizado da realidade social e espacial. Esta ausência de concretude o restringiria a um campo puramente normativo, impedindo-o de se transformar em um novo Nomos. Suas regras, por conseguinte, acabariam limitadas ao plano deontológico, uma vez que supõem a igualdade de direitos como um atributo apriorístico associado à própria condição de Estado nação, em uma analogia precária com a ideia de direitos humanos. A igualdade de direitos e o equilíbrio entre os soberanos que vigia no contexto do Ius publicum europaeum, por sua vez, não tinha esse componente abstrato e universal, já que enraizada uma base concreta: a divisão do espaço em unidades territoriais estatais que compartilhavam recursos e valores relativamente próximos, pois circunscritos ao continente europeu (Schmitt, 1993). Era esta concretude que lhe garantia efetividade enquanto principio de ordenação das relações internacionais capaz de impedir a eclosão de conflitos de aniquilação mútua em solo europeu por mais de duzentos anos. A pretensão de universalidade da ordem implementada no século $\mathrm{XX}$ pôs em xeque essa relativa igualdade concreta atrelada ao conceito de Estado, tendo em vista sua aplicação a coletividades políticas radicalmente distintas entre si.

Para Schmitt, a construção do primeiro Nomos da terra como ordenação concreta do espaço global, capaz de promover um conceito de guerra que permite a limitação e a humanização da mesma, está diretamente associada ao surgimento dos Estados em dois sentidos. Primeiro, por permitir o estabelecimento de uma organização espacial efetiva do plano internacional, baseada em unidades territoriais que se reconheciam mutuamente como iguais, fazendo com que a Europa surgisse como um espaço ordenado no qual as fronteiras "não implicavam exclusão mas reconhecimento mútuo, sobretudo, o reconhecimento de que o solo do vizinho do 
outro lado da fronteira não carece de dono (Schmitt, 1950: 29)." Em segundo lugar, porque o Estado foi capaz de promover uma secularização na lógica da guerra, que permitiu o afastamento dos conceitos teológicos e morais de justa causa, -os quais se baseavam na discriminação do inimigo- em nome de um conceito jurídico formal de guerra justa, que determinava o respeito entre os combatentes, que passaram a se reconhecer como iusti hostes ${ }^{3}$. Isto é, soberanos legítimos e, por isso, sujeitos aos mesmos direitos e deveres. Essa relativização da inimizade, para Schmitt, representa uma 'evolução da razão' por parte dos europeus, permitindo-lhes dar um passo significativo em termos de um conceito racional e humanitário de guerra (Schmitt, 2001).

$\mathrm{Na}$ ordem westphaliana, portanto, não havia nenhuma autoridade efetiva que não os Estados, absolutamente soberanos na elaboração dos princípios e regras que orientavam suas ações. Nesse contexto, por conseguinte, a validade de tais princípios era condicionada exclusivamente ao pertencimento à categoria de Estados-nação, associada ao reconhecimento mútuo da legitimidade de cada soberano como autoridade máxima em seu território e, por isso, sujeito dos mesmos direitos e deveres em relação com os outros soberanos, que comungam de igual status e possuem os mesmos direitos ${ }^{4}$.

\footnotetext{
3 Ou seja, inimigos que se reconhecem como justos e possuidores dos mesmos direitos e deveres, uma vez que pertencem à mesma categoria de Estado nação.

${ }^{4}$ Por isso, para Schmitt, o cenário internacional europeu se aproxima do Estado de Natureza hobbesiano no tocante às suas propriedades anárquicas, tendo em vista a ausência de uma autoridade superior aos sujeitos que o compõem, porém não pode ser enquadrado nessa categoria. No caso da Europa na era moderna, os Estados tinham suas relações permeadas por noções de direito que regulavam as relações entre as partes, impedindo que este estado anárquico se traduzisse em caos, ou em uma guerra civil internacional (Rasch, 2005).
} 


\section{O ocaso do primeiro Nomos da Terra e o surgimento do Großraum como nova forma de ordenamento do espaço}

Apesar de sua nostalgia pelo sistema estatal westphaliano, Schmitt fora perspicaz em perceber suas transformações, antecipando-se ao debate contemporâneo acerca da globalização.

Já na década de 30, ele havia concluído que o Estado-Nação, não sobreviveria intacto ao incremento de uma economia mundial cada vez mais desterritorializada e integrada (Galli e Fay, 2010). Nessa nova conjuntura, as discrepâncias entre os Estados, aumentam de tal forma, que o conceito de soberania não pode mais ser igualmente aplicado para todos que se enquadram nesse status. É o caso dos países cujos vínculos de dependência econômica são tão fortes, que sua capacidade de tomar decisões sem levar em consideração as pressões externas é quase nula (Stirk, 1999). Assim sendo, dada sua fragilidade perante as demandas de um mercado cada vez mais voraz, é, de certa forma, conveniente para este tipo de economia, uma associação, ainda que subalterna, a uma potência regional, capaz de garantir mercado consumidor, investimentos e, quando necessário, crédito5.

Quando aplicada ao fenômeno de regionalização, o Großraum, enquanto categoria espacial situada entre o Estado e o universo, torna-se fundamental para compreendermos a conjuntura que deflagra com o fim da Guerra Fria. Conforme o argumento aqui desenvolvido, embora seja passível de enquadrar a situação da Alemanha na configuração atual da União Européia, o conceito de Großraum, fora concebido em um momento anterior ao estabelecimento da hegemonia econômica e política do país, uma vez que o autor, falecido em 1985, não viveu para ver sua pátria finalmente assumir a posição de Reich, em face aos demais países do continente. Nesta medida,

5 A relação entre México e Estados Unidos ilustra perfeitamente esse tipo de associação subalterna. 
Schmitt usa como referência o estabelecimento da Doutrina Monroe, por meio da qual os Estados Unidos teriam manifestado a intenção de estabelecer o continente americano como sua área de influência.

No início do século XX, especialmente durante o Terceiro Reich, muitos intelectuais alemães se dedicaram à elaboração de conceitos espaciais que pudessem auxiliar a embasar ou criticar as pretensões expansionistas do regime. Nesse sentido, a Raumtheorie, ou teoria do espaço, ganha notoriedade (Stirk, 1999). Como era de se esperar, a contribuição de Schmitt para esse debate assume um caráter polêmico, uma vez que seu conceito de grande espaço (Großraum) se contrapõe ao de Lebensraum (espaço vital), elaborado por Karl Haushofer, para legitimar, a partir de justificativas biológicas e raciais, o direito de um país de adquirir um território compatível com as necessidades de sua população. A principal distinção entre ambos conceitos decorre diz respeito ao determinismo racial, substituído na teoria schmittiana por determinantes econômicos e pela noção de "idéia política", apresentados como elementos constitutivos do Großraum.

Nesta definição, ganha destaque o papel da dimensão ideológica na formação desses espaços políticos, demarcando a distinção do conceito schmittiano no escopo da Raumtheorie e em relação a quaisquer outras categorias que atribuam um caráter "natural" à gênese das unidades políticas nacionais ou supranacionais. O Grossraum é, portanto, uma demarcação espacial que agrupa um conjunto de países, em função debilidades econômicas e da adesão a uma "idéia política particular”, ou seja, uma decisão normativa. É exatamente pelo caráter convencional e normativo de sua gênese que podemos diferenciar os conceitos de Großraum e de Lebensraum, tornando o primeiro mais afeito à caracterização dos blocos econômicos atuais.

A "idéia política", para Schmitt, é uma decisão que sempre implica na noção de exclusão de um inimigo determinado, por exemplo, no caso da Doutrina Monroe, a exclusão da ingerência européia nos rumos políticos do Hemisfério Ocidental, o qual a partir de então 
se constitui como Großraum. A potência que representa essa "idéia política”, responsável por definir o pertencimento ao Großraum é denominada por Schmitt, pelo conceito de Reich "the major power representing a distinct political idea and resisting intervention by foreign powers in its Raum" (Bendersky, 1983: p. 254). A noção de Reich é utilizada para designar a potência líder do Großraum, que desempenha um duplo papel dentro desse espaço: no plano simbólico, ela é responsável por representar a "idéia política" que constitui o elemento de identificação entre as nações no interior do bloco; no plano material, por sua vez, o papel do Reich é defendêlas de intervenções por parte de potências estrangeiras. Seguindo a lógica hobbesiana sintetizada no binômio proteção x obediência, em contrapartida a esta proteção, a potência líder reivindica o direito de intervir econômica e politicamente nos países que compõem sua área de influência conforme seus interesses particulares, ainda que muitas vezes estes se encontrem escamoteados retoricamente (Ulmen, 1987).

Diante de tal definição, originalmente associada à hegemonia norte-americana na América Latina (Idem), torna-se possível fundamentar a pertinência da hipótese que estrutura o presente trabalho, acerca da pertinência das ferramentas teóricas encontradas na obra internacionalista de Schmitt para a caracterização da conjuntura atual, na qual a Alemanha ocupa o papel Reich do Großraum, europeu.

No que diz respeito à América, os Estados Unidos ao proclamarem a Doutrina Monroe, se estabelecem como o Reich, isto é como defensores da independência do Hemisfério Ocidental perante a Europa, não apenas no tocante ao seu território como a todo o continente, que passa a ser definido co1mo sua área de interesse ${ }^{6}$. Schmitt, então, atribui à emergência dessa nova forma de ordenar o espaço, um

6 "A Doutrina Monroe e o Hemisfério Ocidental são dois conceitos que desde o início estão unidos e designam o âmbito dos special interest dos Estados Unidos" (Schmitt; 1950: 364). Pois, não podemos esquecer que ela anuncia a "América para os americanos" 
papel crucial na dissolução do primeiro Nomos da terra. Isto porque, a nova categoria vai de encontro ao caráter eurocêntrico do antigo sistema, transferindo o centro ordenador para o continente americano. Mas, sobretudo, porque a demarcação da linha do Hemisfério Ocidental e a definição do Großraum americano, enquanto unidade política que ultrapassa as fronteiras estatais, determinam o início da decadência do Estado-Nação e do Ius publicum europaeum, tendo em vista a importância do mesmo na ordem westphaliana .

Ao sucederem a Inglaterra em seu posto de major player do cenário internacional, os EUA precisavam de um princípio de legitimidade para justificar a expansão de seu poderio. Para Schmitt, no caso do imperialismo norte-americano esse princípio fora encontrado na esfera econômica. Nesse sentido, eles adotam uma política que se estrutura a partir do binômio presença (econômica) x ausência (política) a qual condiz com a essência marítima desse país, pois representa a primazia conferida à esfera econômico-privada, em detrimento do âmbito políticoestatal.

Os EUA, como outrora fizera a Inglaterra, estruturaram seu poder a partir do mar, ou seja, a partir do comércio e da economia (Schmitt, 1979). Surge, então, um ponto em que sobressai a diferença entre uma ordem estruturada como um Nomos da Terra e uma ordem que se configura como um Großraum. Na primeira, a diretriz fundamental que pautava as relações interestatais era o igual reconhecimento e o respeito à soberania de cada Estado, compreendidos como igualmente soberanos. No novo contexto, a categoria de soberania passa por um processo de transformação, no qual seu sentido torna-se cada vez mais abstrato. A soberania, enquanto monopólio de decisão estatal em todos os assuntos que digam respeito à esfera pública, deixa de ser um atributo igualmente compartilhado por todos os Estados (Gali, 2010).

Assim como ocorre atualmente com algumas nações europeias, notadamente aquelas sob os auspícios da Troika, no caso do Großraum 
americano, conforme a descrição de Schmitt, a soberania das nações integradas sob o auspício de um Reich é relativizada por tratados internacionais que respaldam sucessivas intervenções políticas e, sobretudo, econômicas por parte da potência hegemônica. Esses dispositivos - análogos aos que hoje constituem a União Europeia, guardadas as devidas proporções - garantiam aos EUA o direito de intervir de forma legítima, na política e na economia das outras nações que fazem parte de sua esfera de influência. Por isso, a existência de um Großraum, pressupõe tanto a emergência de um Reich, enquanto potência regional cujo poder transborda as fronteiras estatais, como de "sub estados", que têm sua soberania por ele violada. Essa diferenciação esvazia o conteúdo concreto que o conceito de Estado possuía no Ius publicum europaeum, necessariamente associado à igualdade jurídica entre as unidades políticas por ele designadas (Campi, 2007).

A Alemanha é, portanto, o Reich, do Großraum europeu porque, em última instância detêm o controle econômico e político da região, a despeito da soberania das outras unidades que compõem sua área de influência. Dessa forma, utilizando as ferramentas teóricas encontradas na obra de Carl Schmitt, é possível afirmar que, apesar de retoricamente associada a um discurso de separação entre economia e política, a influência econômica alemã se fundamenta em sua capacidade política de determinar a observância de seus interesses, em detrimento da soberania política dos outros Estados, relegada cada vez mais a um posto meramente simbólico.

Este tipo de ordenação, no entanto, difere do imperialismo clássico, no qual uma unidade política absorve outras, que passam a constituí-la. No Großraum, as unidades políticas não se dissolvem, mantendo uma separação formal. Elas permanecem sendo países distintos, embora não sejam completamente soberanos. A potência líder detém a capacidade de influenciar diretamente na esfera política das outras unidades, ainda que na maioria das vezes esse poder se manifeste por meio de intervenções econômicas (Otero, 
2005). Sob a lógica do autor, esta seria a característica central de uma forma moderna de direção cuja característica primordial é a renúncia à anexação territorial aberta do Estado dirigido ${ }^{7}$.

Seu resultado é o enfraquecimento do Estado-nação enquanto unidade concreta de ordenação do espaço, detentora do monopólio da decisão última dentro de suas fronteiras, visto que, no caso das subunidades do Großraum, a soberania é reduzida a um espaço vazio para processos sócioeconômicos ${ }^{8}$. Deste modo, os países sujeitos à intervenção da potência líder, não podem ser considerados completamente soberanos, pois acabam tendo que colocar os seus interesses em segundo plano. Nesse sentido, podemos dizer que o verdadeiro soberano é aquele que detém o poder sobre a economia - cuius economia, eius regio. Não obstante, como ressalva Schmitt, essa capacidade de intervenção não pode ser vista como puramente econômica uma vez que, ela é ao mesmo tempo causa e conseqüência de um poder político.

Essa perspectiva teórica torna-se, pois, útil para demonstrar a transformação ocorrida no conceito de soberania na passagem de uma ordem, terrestre e estadocêntrica, para outra estruturada a partir de valores essencialmente maritimos que dizem respeito a liberdades privadas e à economia. Nesta nova conjuntura, mais comumente compreendida pelo conceito de globalização, o Estado e a política perderam sua primazia (Gali e Fay, 2010: 21).

\section{Conclusão}

No campo das Relações Internacionais, a maioria das reflexões acerca das transformações ocorridas ao longo do século XX res-

\footnotetext{
${ }^{7}$ Schmitt; 1950: 320

8 Idem
} 
saltam o caráter de ruptura deste período em relação ao passado. Porém, ao mesmo tempo em que pululam as diferenças conquanto aos séculos anteriores, torna-se difícil encontrar um consenso na literatura no tocante as suas características fundamentais. Em resumo, nacionalismo, universalismo e, posteriormente, regionalismo sobressaem como chaves analíticas concorrentes.

Se até a Primeira Guerra Mundial, nacionalismo e estadocentrismo mantinham-se consensuais enquanto princípios determinantes na articulação entre espaço e autoridade, já no entre guerras, com o surgimento da Liga das Nações, espraia-se o sonho kantiano de conformação de uma nova ordem, organizada segundo determinações universalistas. Contudo, em pouco tempo, este projeto foi, de certo modo, subsumido pela emergência de uma ordem bipolar, na qual o mundo se divide em dois blocos capitaneados por duas potências portadoras de ideias políticas distintas.

Todavia, a derruição da ordem bipolar, mediante a debacle da URSS, não foi seguida da emergência de um novo princípio consensual no tocante à ordenação do espaço - a despeito do triunfalismo em torno da vitória do capitalismo e da democracia liberal que, nos anos 90, deram a alguns a impressão de que o mundo enfim seguiria rumo ao uma ordem universalista, arregimentada sob a liderança dos EUA. Ao contrário, sucedeu-se a emergência de um mundo multipolar, posto que dividido em diversos blocos, uns mais determinantes e rígidos e outros mais fluidos e menos determinantes para a vida dos povos que os compõem. Nesta nova (des)ordem mundial observa-se, pois, a concorrência de princípios antitéticos como nacionalismo, cosmopolitismo, solidariedade política e interesse econômico, alternando-se (muitas vezes de modo arbitrário) nos discursos que compõem o auto-entendimento das unidades políticas estatais, sub estatais, interestatal se supranacionais.

Sob essa perspectiva, sobretudo quando considerada a situação atual da Europa, fica clara a relevância da hipótese schmittiana 
acerca da configuração de uma ordem pós-nacional, na qual a ideia de Estado nação perderia espaço para o conceito de Großraum, enquanto categoria concreta de divisão e ordenamento do espaço em um mundo que se divide em blocos compostos por diversas nações em situação de interdependência mútua. De acordo com Schmitt, quando contrastado ao universalismo, que caracteriza as investidas cosmopolitas de configuração de uma ordem global a partir de uma autoridade mundial, o regionalismo surge como uma alternativa mais concreta e eficaz para o ordenamento do sistema internacional.

Sendo assim, sobre as premissas realistas extraídas da obra do autor, é plausível sustentar uma hipótese relativamente otimista, acerca do estabelecimento de um novo equilíbrio de poder, cuja implementação alicerçaria um sistema jurídico eficaz na tarefa de regular as relações entre os povos, desde que fosse assumida a hegemonia deste novo princípio de articulação entre espaço e autoridade. O Großraum, enquanto categoria espacial concreta, seria o elemento definidor dessa nova ordem, visto que responsável por articular direito e espaço, ordenação (Ordnung) e localização (Ortung) (Schmitt, 1993) e (Campi, 2007). No entanto, essa conclusão otimista tem como condição o abandono das pretensões idealistas de construção de uma ordem global baseada nos princípios universais simbolizados pela Declaração Universal de Direitos Humanos e pela Organização das Nações Unidas (ONU) ${ }^{9}$. Por enquanto, todavia, seguiremos sob a égide da indefinição entre universalismo, nacionalismo e regionalismo; entre uma ordem estruturada a partir da divisão concreta do poder por diferentes esferas de intervenção,

\footnotetext{
9 No entanto, seguindo o argumento schmittiano, o universalismo cosmopolita não pode sequer ser considerado uma ordem, pois, não é capaz de se traduzir em uma estrutura espacial na qual se alicerçarão os princípios do Direito Internacional. Suas normas e princípios são incapazes de funcionar, de fato, como instrumento de mediação de conflitos, que, na ausência de regras efetivas, tornam-se cada vez mais violentos e desproporcionais.
} 
com seus subsequentes círculos culturais coexistentes, e o projeto kantiano de uma Humanidade reunida por laços de fraternidade em uma federação global de Estados.

A Europa, por sua vez, transforma-se num cenário exemplar para a demonstração de tal indefinição, haja vista a disputa entre discursos antitéticos, quer associados à valorização do nacionalismo e da autonomia dos povos - que, em alguns casos emergiriam da segmentação de Estados multinacionais existentes -; quer à miríade federalista, que pode ser entendida como uma adequação do projeto kantiano às fronteiras europeias (Habermas, 2012). Ainda que, como já nos alertava Carl Schmitt na década de 50, assim como no passado fizeram os americanos com a Doutrina Monroe, o sonho de uma federação europeia resulte em uma ideia política, responsável por estruturar e legitimar a conformação de um Grossraum, sob os auspícios do Reich Alemão.

\section{Referências}

Aravamudan, Srinivas (2005), "Carl Schmitt's The Nomos of the Earth: Four Corollaries". South Atlantic Quarterly, 104(2), 227-236.

Bendersky, Joseph (1987), "Carl Schmitt and Nuremberg". Telos Press, July (72), 91-96.

Bendersky, Joseph (1983), Theorist for the Reich . Princeton: Princeton University Press Univ.

Buchard, Christoph (2006), "Interlinking the Domestic with the international: Carl Schmitt on Democracy and International Relations". Leiden Journal of International Law, 19, 9-40.

Campi, Alessandro (2007), "Gran espacio y unidad política del mundo". In : Corbetta, Juan Carlos; Piana, Ricardo Sebastián (orgs). Política y orden mundial, ensayos sobre Carl Schmitt. Buenos Aires : Prometeo Libros, 63-79.

Dyzenhaus, David (1997), Legality and Legitimacy. Nova York: Oxford University Press.

Ferreira, Bernardo (2004), O Risco do Político: crítica ao liberalismo e teoria política no pensamento de Carl Schmitt. Belo Horizonte e Rio de Janeiro: Editora UFMG/ IUPERJ.

Freund, Julien (2007), "Las líneas clave del pensamiento político de Carl Schmitt". In Corbetta, Juan Carlos; Piana, Ricardo Sebastián (orgs). Política y orden mundial, ensayos sobre Carl Schmitt. Buenos Aires : Prometeo Libros, 25- 63. 
Galli, Carlo; Fay, Elisabeth (2010), "Carl Schmitt and the Global Age". CR: The New Centennial Review, 10 (2), 1-25.

Habermas, Jürgen (2012), Sobre a constituição da Europa: um ensaio. São Paulo: Unesp.

Luoma-Aho, Mika (2000), "Carl Schmitt and the Transformation of Political Subject". The European Legacy, 5 (5), 703-716.

Otero, Carlos A (2005), "From the Nomos to the Meridian". The South Atlantic Quarterly, 104 (2), 381-388.

Peter Stirk (1999), “Carl Schmitt's Völkerrechtliche Großraumordnung”. History of Political Thought, XX (2), 357-374.

Rasch, William (2005), "Lines on the Sand: Enmity as a Structuring Principle". The South Atlantic Quarterly, 104 (2), 253-262.

Sá, Alexandre Franco (2004), Metamorfose do Poder: Prolegómenos Schmittianos a toda a sociedade futura. Coimbra: Ariadne Editora.

Scheuerman, William (2006), "Carl Schmitt and Hans Morgenthau: Realism and Beyond". Institute of German Studies, 09 (22), 62-92.

Schmitt, Carl (1992), O Conceito do Político. Petrópolis, Vozes.

Schmitt, Carl (1979), El Nomos de la Tierra em el Derecho de Gentes del Jus Publicum Europaeum. Madrid: Centro de Estudios Constitucionales.

Schmitt, Carl (1952) Tierra y mar: consideraciones sobre la historia universal. Madrid: Instituto de Estudios Políticos.

Schmitt, Carl (1992), El Leviatahan em la teoría del Estado de Tomás Hobbes. Buenos Aires: Editorial Struhart \& Cía.

Schmitt, Carl (2001) "El Imperialismo Moderno en el Derecho Internacional Público". in: Aquilar, Hector (ed). Carl Schmitt, Teólogo de la Política. Cidade do México: Fondo de Cultura Econômica.

Schmitt, Carl (2001) "Enemigo Total, Guerra Total". in: Aquilar, Hector (ed). Carl Schmitt, Teólogo de la Política. Cidade do México: Fondo de Cultura Econômica.

Schmitt, Carl (2001) "La relación entre los conceptos de guerra y enemigo". in: Aquilar, Hector (ed). Carl Schmitt, Teólogo de la Política. Cidade do México: Fondo de Cultura Econômica.

Schmitt, Carl (2007), Theory of the Partisan: Intermediate Commentary on the Concept of the Political. Nova Iorque: Telos Press.

Schmitt, Carl (2003), "Appropriation/Distribution/Production: An Attempt to Determine from Nomos the Basic Questions of Every Social and Economic Order". In: Schmitt, Carl. The Nomos of the Earth in the International Law of the Jus Publicum Europaeum. Nova Iorque: Telos Press, 324-35.

Schmitt, Carl 1962), "El orden del mundo después de la Segunda Guerra Mundial". Revista de estudios políticos,122, 19-38.

Schmitt, Carl 1997), "Revolução legal mundial: superlegalidade e política". Lua nova, 42, 90-117.

Ulmen, Gary (1987), "American Imperialism and International Law: Carl Schmitt on the US in World Affairs". Telos, 72, 43-71.

Zarmanian, Thalin (2006), "Carl Schmitt and the Problem of Legal Order: From Domestic to International". Leiden Journal of International Law, 19, 41-67. 